\title{
PROTEIN DENATURATION BY IONIZING RADIATION AND ROLE OF OXYGEN
}

\author{
MASARU WAKABAYASHI, FUMIO KAWAMURA \\ AND JUNKICHI OKIDATE* \\ Department of Medical Radiology, Hokkaido University
}

Certain physicochemical processes may take place between the radiation energy absorption in target and its final expression in reaction of an organism. Little is known about these processes $(1,2,12)$. It is the purpose of the work reported here to throw some light upon this field by causing denaturation of protein by irradiation and investigating the role of oxygen.

It was already reported by the writers (3) that serum protein is denaturated by a large dose of X-ray. In order to study these phenomena protein solution was used and the denaturation caused by irradiation with gamma-ray from $\mathrm{Co}^{60}$ was measured by means of paper electrophoresis and at the same time "oxygen effect (4)" which was pronounced in view point of radiation chemistry was also studied.

MATERIALS AND METHOD

The concentration of "gamma-globulin" solution (Nichiyaku Co.) used is $68 \mathrm{mg} / \mathrm{cc}$. $\left(p_{\mathrm{H}} 7.7\right)$. This solution is packed in a small glass vessel and irradiated $1 \times, 10 \times, 50 \times 10^{5} \mathrm{r}$. respectively by gamma-ray from $\mathrm{Co}^{\epsilon 0}$ with intensity of $2,500 \mathrm{r} / \mathrm{min}$. Paper electrophoretic examination $(5,6)$ was carried out with irradiated and non-irradiated samples. Filter paper used was Toyo filter paper No. 51 whose size is $11 \times 25 \mathrm{~cm}$. A fixed volume of each sample $(0.02 \mathrm{cc}$. $)$ was placed by a micropipette on the base line of the test paper. The electrophoresis was carried out with the veronal buffer solution $\left(p_{\mathrm{H}} 6.8\right.$; ionic strength, 0.1$)$ for 10 hours $(6-10 \mathrm{~V} / \mathrm{cm}$.) at room temperature.

After drying off these papers were developed by bromphenolblue solution and 5\% acetic acid. The density of colour of the papers was measured by photoelectric colorimeter and plotted against the mobility of each fraction on the section paper to take the electrophoretic pattern.

RESULTS

Experiment 1. On changes in the electrophoretic pattern by gamma-ray irradiation.

The electrophoretic pattern of "gamma-globulin" solution is shown in fig.

Received for publication October 13, 1955.

* 若林 勝 河村文夫 沖舘純吉 
1, $A$ and fig. 2, A. As regard to this pattern it was observed that "gammaglobulin" solution used was not pure but it contained a large amount of betaglobulin and small amount of alpha-globulin and of albumin.

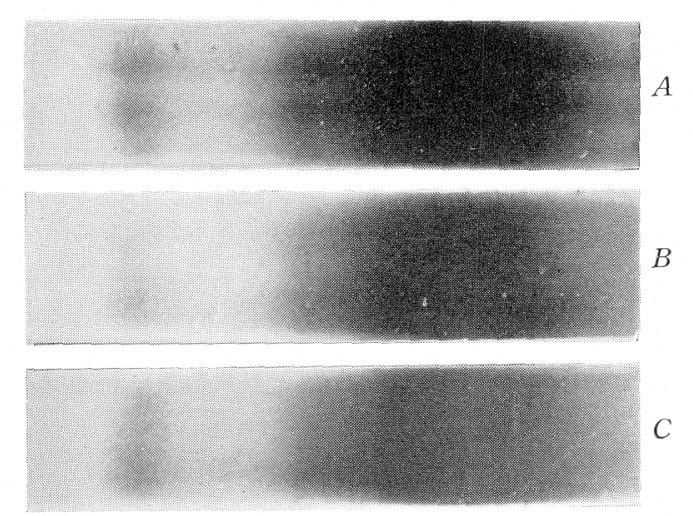

FIG, 1

FIG, 1. Paper-electrophoretic picture.

$A$ : Non-irradiated. $B$ : Irradiated with $5 \times 10^{6} \mathrm{r}$. in peresence of oxygen. $C$ : Irradiated with $5 \times 10^{6} \mathrm{r}$. in absence of oxygen.

FIG. 2. Electrophoretic pattern.

$A$ : Non-irradiated. $B$ : Irradiated with $10^{5} \mathrm{r}$. $C$ : Irradiated with $10^{6} \mathrm{r}$. $D$ : Irradiated with $5 \times 10^{6} \mathrm{r}$.
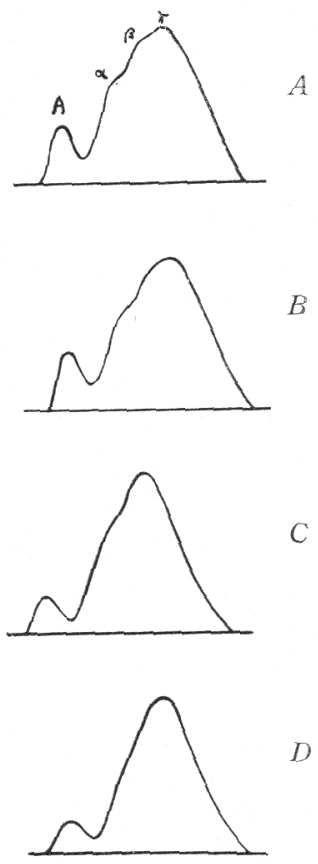

FIG. 2

When these samples were irradiated with doses ranging from $10^{5}$ r. to 5 $\times 10^{6} \mathrm{r}$., marked changes in pattern occurred as shown in fig. $2, B, C, D$ and fig. 1, $B$ i.e. gamma-globulin fraction showed marked decrease and its peak came near to beta-globulin fraction. Also beta-globulin fraction came near to gamma fraction. As the dose was increased, the tendency of approaching of the two fractions increased. When $5 \times 10^{6} \mathrm{r}$. was irradiated, the peak of gamma-globulin and that of beta-globulin disappeared and formed only a peak which lay in middle of the two peaks (fig. 3 and fig. 2, D). After irradiation was ceased these changes showed no further progress. From these experiments it was presumed that gamma and beta-globulin were changed in their mobility and were denaturated

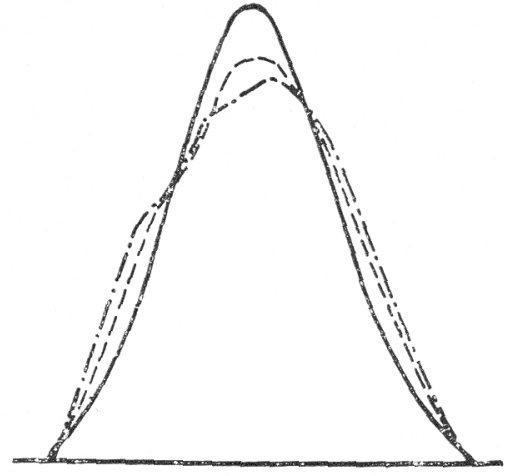

FIG. 3. Electrophoretic pattern of globulin fraction.

Chain line, non-irradiated. Broken line, irradiated with $10^{6} \mathrm{r}$. Full line, irradiated with $5 \times 10^{6} \mathrm{r}$. 
by gamma-ray irradiation. This results are identical with those of the serum protein irradiated with X-ray, previously reported by Wakabayashi and Kawamura (3). Further more the electrophoretic pattern of serum denaturated by ultra-violet irradiation (7) showed results similar to those obtained by gamma and $\mathrm{X}$-irradiation.

Experiment 2. On the role of oxygen in denaturation of protein by irradiation.

From view of radiation chemistry, it may be said that a primary action of radiation in aqueous solution makes various kinds of free radicals from water (2). And the amount of reactive group produced corresponds to the amount of oxygen contained in solution. So the effectiveness of radiation is influenced by the amount of reactive group and that of oxygen present in the time of irradiation (8).

In order to examine the role of oxygen in protein denaturation caused by irradiation, protein solution whose sample was evacuated for 30 minutes by means of a vacuum pump was irradiated by gammaray with dose of $5 \times 10^{6} \mathrm{r}$. The electrophoretic pattern of this sample showed only a slight difference from that of non-irradiated (fig. 4 and fig. 1,C). The fact that when oxygen concentration is very low the effect of radiation shows a remarkable decrease has been recognized in this experiment also (8).

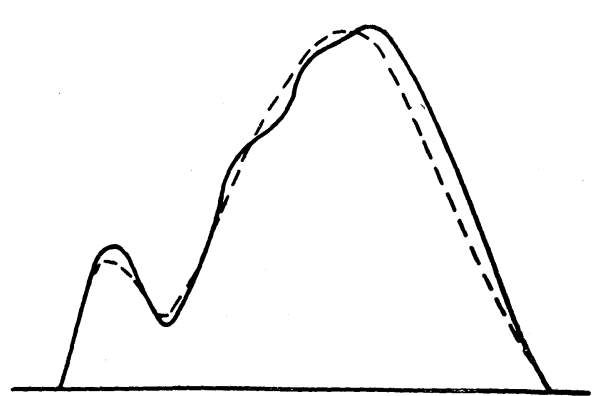

FIG. 4. Influence of oxygen.

Broken line, irradiated with $5 \times 10^{5} \mathrm{r}$. in absence of oxygen. Full line, non-irradiated.

The question arises as to the role of oxygen: Has oxygen to change the production of reactive groups or has it to react with any changed protein molecules produced by irradiation?

Experiment 3. On the consumption of oxygen by protein during irradiation.

To examine the above question, the concentration of oxygen in protein solution was measured before and immediately after irradiation by means of oxygraphy (9). Samples were kept air tight and irradiated by gamma-ray with dose of $5 \times 10^{6} \mathrm{r}$.

It showed a remarkable difference between the relative concentrations before and after irradiation. The concentration after irradiation was much lower as compared with that before irradiation (fig. 5).

During the irradiation some portion of the oxygen present in the solution may be used for the production of reactive groups, but it may be a very small portion as compared with the total amount of oxygen present $(1,2)$. So it is presumed that the decrease of oxygen concentration by irradiation was caused by consumption of oxygen by protein. 
$A$

$B$

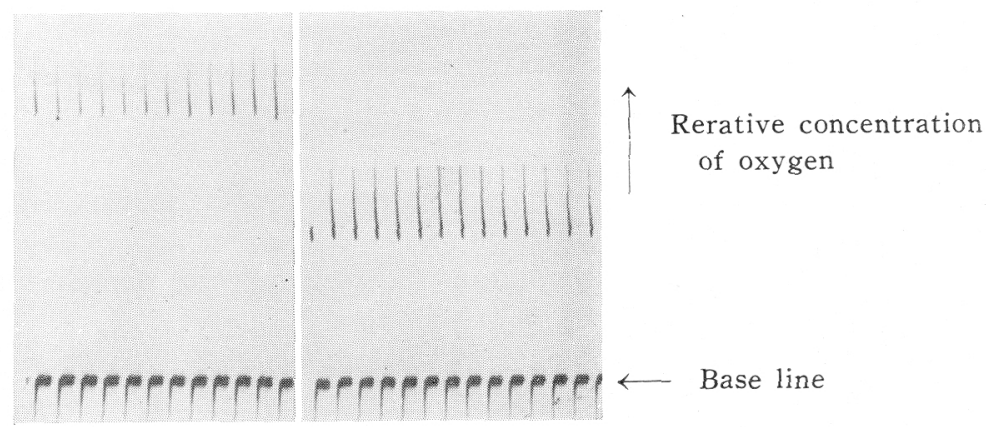

FIG. 5. Oxygramm of protein solution in closed vessel. $A$ : Before irradiation. $B$ : After irradiation with $10^{6} \mathrm{r}$.

\section{DISCUSSION}

The writers $(8,13)$ have reported that free energy produced by irradiation was given to target either directly or indirectly. This energy spreads in structure of the target area and causes an excitated state of that whole area. This energy spread causes photochemical reactions in a wide sense and gives activation energy to various bonds or structure with the results that it causes intramolecular bondes to break and various further changes in reactivity of constituent molecules in the target. In this case target is a protein molecule itself. It was already investivated on serum protein by Wakabayashi and Kawamura (3).

These facts lead the writers to postulate that the irradiation activates protein molecule and in turn changes the reactivity of protein.

The role of oxygen may be considered as follows: The concentration of oxygen in the solution showed a marked decrease after irradiation and when the concentration of oxygen was very low, irradiation caused no changes in the electrophoretic patterns. From these facts it may be said that, when the protein molecule is charged with energy, its reactivity changes and it becomes very easy to react with oxygen. After irradiation was ceased the protein solutions showed no increase in denaturation, indicating that the reactivity changed by irradiation returns to its stable state in a very short period.

Similar phenomena occur also in the case of irradiation with ultraviolet light. When protein solutions are exposured to ultraviolet light, they absorb oxygen and undergo denaturation. This protein denaturation does not occur in the absence of oxygen. Arnow (10) showed that the protein denaturation due to ultra-violet light was caused by change of tyrosine group which reacted with oxygen and converted to dopa. One of the writers (Kawamura (11)) also found the identical phenomena with X-ray irradiation.

From the above facts it is concluded that oxygen plays role in reacting with protein molecule activated by radiant energy absorption, resulting in irreversible denaturation. 
SUMMARY

Protein solutions were irradiated with doses $\left(10^{5} \sim 5 \times 10^{5} \mathrm{r}\right.$. $)$ of gamma-ray from $\mathrm{Co}^{60}$.

1. The peaks of gamma- and beta-globulin begin to approach as the dose increases and make only one peak which lies in the middle of two fractions.

2. When the concentration of oxygen present in protein solution is very low, irradiation causes no denaturation of protein.

3. The oxygen concentration in solution shows a marked decrease after irradiation as compared with that before irradiation.

4. The mechanism of protein denaturation produced by irradiation and the role of oxygen were discussed. study.

The writers would like to thank Dr. T. Anso for his helpful assistance given to this

This study has undergone Grant in Aid for Fundamental Scientific Research (1955).

\section{REFERENCES}

1. D. E. LEA. Actions of Radiations on Living Cells, 2nd. Ed. England: Cambridge University Press, 1955.

2. J. J. Nickson, ed. Symposium on Radiobiology. New York: John Wiley and Sons, 1952.

3. M. WAKabayashi And F. KaWAmura. Monogr. Res. Inst. Appl. Elec. 2 : 1, 1951.

4. E. S. G. BARRON. Rad. Res. 1: 109, 1954.

5. W. Grassmann And K. Hannig. Hoppe-Seylers Z. Physiol. Chem. 290 : 1, 1952.

6. M. KobAyASHi. Jap. Med. J. No. 1562: 25, 1954.

7. B. D. Davis. J. Biol. Chem. $146: 163,1942$.

8. M. Wakabayashi And F. Kawamura. Monogr. Res. Inst. Appl. Elec. 5 : 91, 1955.

9. M. Mochizuki. Monogr. Res. Inst. Appl. Elec. 2 : 39, 1951.

10. L. E. ARnow. J. Biol. Chem. $120:$ 151, 1937.

11. F. Kawamura. Nipp. Act. Radiol. 11 : (10), 1, 1952.

12. F. DesSAUER. Str. ther. 94: 29, 1954.

13. M. Wakabayashi. Jap. Med. J. No. $1579:$ 7, 1954. 